\title{
Redes de apoio social à família de pessoas com problemas decorrentes do uso de drogas: percepção de familiares cuidadores
}

Social support networks for the family of people with problems resulting from drug use: perception of caregivers relatives

Redes de apoyo social para la familia de personas con problemas derivados del consumo de drogas: percepción de los cuidadores familiares

Ronaldo Rodrigues Pires ${ }^{1 *}$, Alexsandro Batista de Alencar ${ }^{2}$, Luana Vieira de Carvalho ${ }^{1}$, Francisco Diones Araujo Rodrigues ${ }^{1}$, Raquel Cerdeira de Lima ${ }^{3}$, José Jackson Coelho Sampaio.

\section{RESUMO}

Objetivo: Compreender quais são as redes de apoio social utilizadas por familiares cujos membros fazem uso problemático de drogas e como estes avaliam o apoio recebido. Métodos: Trata-se de estudo de natureza qualitativa conduzido com familiares que acompanhavam usuários de um Centro de Atenção Psicossocial álcool e outras drogas. Foram realizadas entrevistas e a análise das informações coletadas foi baseada na técnica da Análise de Conteúdo. Recebeu aprovação ética com o parecer CAAE: 45607515.9.0000.5534. Resultados: Os resultados indicaram que, por um lado, a própria família e instituições religiosas formam a principal rede de apoio social informal. Por outro, o Centro de Atenção Psicossocial álcool e outras drogas, Unidade de Pronto Atendimento e hospital psiquiátrico compõem a rede de apoio social formal. Estes últimos apresentam-se desarticulados e pouco acolhedores às demandas dos familiares. Considerações finais: As redes de apoio sociais dos sujeitos desta pesquisa são constituídas por um reduzido repertório de pessoas e lugares. Desse modo, impõe-se a reflexão sobre a urgência de integrar espaços do território como potenciais produtores de acolhimento e cuidado, envolvendo a pessoa que usa drogas, sua família e a comunidade.

Palavras-chave: Apoio social, Família, Saúde mental, Transtornos relacionados ao uso de substâncias.

\begin{abstract}
Objective: To understand the social support networks used by family members of people who make problematic use of drugs and how they evaluate the support received. Methods: This is a qualitative study conducted with family members who accompanied users of a Psychosocial Care Center for alcohol and other drugs. Interviews were conducted and the analysis of the information collected was based on the Content Analysis technique. Results: The results indicated that, on the one hand, the family itself and religious institutions form the main informal social support network. On the other hand, the Psychosocial Care Center for alcohol and other drugs, the Emergency Care Unit and the psychiatric hospital build the formal social support network. These institutions are disjointed and not very welcoming to the demands of family members. Final Considerations: The social support networks of the subjects of this research are constituted by a reduced repertoire of people and places. Thus, it is necessary to reflect on the urgency of integrating spaces in the territory as potential producers of embracement and care, involving the person who uses drugs, their family, and the community.
\end{abstract}

Keywords: Social support, Family, Mental health, Substance-related disorders.

${ }^{1}$ Universidade Estadual do Ceará (UECE), Fortaleza - CE. *E-mail: ronaldo.pires.psi@gmail.com 2Universidade da Integração Internacional da Lusofonia Afro-brasileira (UNILAB), Redenção - CE. 3Universidade Federal do Ceará (UFC), Fortaleza - CE. 
RESUMEN

Objetivo: Comprender las redes de apoyo social utilizadas por familiares cuyos los miembros hacen uso problemático de drogas y cómo evalúan el apoyo recibido. Métodos: Estudio cualitativo realizado con familiares que acompañaron a los usuarios de un Centro de Atención Psicosocial para el alcohol y drogas. Se realizaron entrevistas y el análisis de la información recopilada se basó en la técnica de Análisis de contenido. Resultados: Los resultados indicaron que, por un lado, la familia misma y las instituciones religiosas forman la principal red informal de apoyo social. Por otro lado, el Centro de Atención Psicosocial para el alcohol y otras drogas, la Unidad de Atención de Emergencia y el hospital psiquiátrico comprenden la red formal de apoyo social. Estos últimos son desarticulados y poco acogedores a las demandas de los familiares. Consideraciones finales: Las redes de apoyo social de los sujetos de esta investigación están constituidas por un repertorio reducido de personas y lugares. Por lo tanto, es necesario reflexionar sobre la urgencia de integrar espacios en el territorio como potenciales productores de acogimiento y atención, implicando la persona que consume drogas, su familia y la comunidad.

Palabras clave: Apoyo social, Familia, Salud mental, Trastornos relacionados con sustancias.

\section{INTRODUÇÃO}

O uso problemático de drogas e sua adequada assistência nos serviços e sistemas de saúde tem sido uma questão relevante, visto as repercussões trazidas para usuários, famílias e para a sociedade em geral (GASPARD JL e LARGACHA SMR, 2016). A produção de estratégias de atenção psicossocial realizadas no território, respeitando os direitos humanos e incluindo a família como parte integrante desse cenário, demandam um esforço compreensivo da complexidade envolvida neste caso.

Ampliar o debate sobre a atenção em saúde mental ao uso de drogas, pensando nas redes de apoio social e a família, como provedora e demandante de cuidados dos serviços de saúde, torna-se uma tarefa relevante para a consolidação do modelo psicossocial de cuidado baseado nos pressupostos da reforma psiquiátrica antimanicomial (HORTA ALM, et al., 2016). Nesse sentido, é preciso conhecer e articular as redes existentes como uma tarefa de suma importância para os serviços de saúde mental do Sistema Único de Saúde (SUS), tendo em vista que o território não se define como um mero espaço de localização geográfica, mas um lugar de produção de subjetividades (BERNARDES A, 2017).

As redes de apoio social podem ser definidas como um conjunto de organizações, formais e informais, que fortalecem os atores sociais em um determinado território. A presença dessas redes aumenta a possibilidade de recuperação da saúde e favorecem a procura e adesão aos serviços (GALVÁN J, SERNA G e HERNANDEZ A, 2008). São capazes, ainda, de darem respostas significativas às manifestações psicopatológicas e situações de crise vividas pelos indivíduos (YUNES MAM e JULIANO MCC, 2015).

Assim, considerando o seu papel essencial no território para a produção do cuidado em saúde mental, tomou-se como objetivo compreender quais são as redes de apoio social, formais e informais, que acolhem os familiares de pessoas com problemas decorrentes do uso de álcool e outras drogas em tratamento em um serviço público de saúde mental. A partir da identificação destas redes, buscou-se, ainda, verificar como os familiares avaliam os agentes e as instituições presentes no seu cotidiano reconhecendo suas potencialidades e fragilidades.

Esta pesquisa foi realizada por meio de um projeto de iniciação científica intitulado: A família do usuário de álcool e outras drogas e suas redes de suporte social. Acredita-se que este trabalho possa contribuir com conhecimentos que subsidiem a produção de um cuidado em saúde mental territorial que tenha a liberdade e o convívio comunitário como princípio ético norteador.

\section{MÉTODOS}

Adotou-se a perspectiva da pesquisa qualitativa, pois, como afirma Bosi MLM (2012), é necessário produzir conhecimento acerca dos aspectos qualitativos dos problemas de saúde, envolvendo os significados e sentidos subjetivos das vivências dos sujeitos, ao mesmo tempo em que buscamos situá-los na dinâmica histórico social. 


\section{Cenário}

A pesquisa foi realizada num Centro de Atenção Psicossocial Álcool e outras Drogas (CAPS ad), em uma capital do Nordeste, pois entre os seis equipamentos existentes neste município, naquele momento, era o único que apresentava atividades de cuidado direcionadas aos familiares.

\section{Participantes}

A escolha dos participantes se deu pelo tipo de amostra intencional. Foram convidados 10 familiares que estiveram presentes em um grupo dedicado ao cuidado da família, promovido pelos profissionais do serviço. Obteve-se, no entanto, anuência de seis familiares, sendo quatro mulheres e dois homens.

\section{Instrumento de produção de informações}

Utilizou-se de entrevistas em profundidade (GASKELL G, 2002), realizadas em encontros agendados em salas de atendimentos do CAPS ad. Foram apresentadas as perguntas: Que pessoas ou lugares tem oferecido ajuda para você junto a este problema com seu familiar? Como você percebe a ajuda recebida por este lugar/pessoa? As falas foram gravadas em áudio e transcritas na íntegra para garantir fidedignidade aos relatos.

\section{Procedimento de análise das informações}

A análise das falas seguiu a metodologia da Análise de Conteúdo, optando pela análise do tipo temática (SANTOS FM, 2012). Como primeiro passo, realizou-se a leitura flutuante do material transcrito construindo os temas e categorias mais frequentes. No segundo passo, os temas e categorias foram explorados, esmiuçando a dimensão subjetiva sobre as redes sociais de apoio citadas e o modo como os familiares avaliaram o apoio recebido. No terceiro passo, ocorreu a interpretação onde os núcleos de sentido atribuídos pelos entrevistados foram analisados levando em consideração os referenciais teóricos da atenção psicossocial, as observações feitas no cenário da pesquisa e o contexto sócio histórico.

\section{Aspectos Éticos}

Este trabalho respeitou as determinações da Resolução 466/2012 e da Resolução no 510/2016 do Conselho Nacional de Saúde. Foi submetido na Plataforma Brasil e aprovado com o parecer CAAE: 45607515.9.0000.5534.

\section{RESULTADOS E DISCUSSÃO}

Uma primeira observação diz respeito a predominância feminina no grupo de entrevistados e no cotidiano do serviço, onde ficou evidente uma frequência maior de mulheres em busca de marcação de consultas para seus familiares, aquisição de remédios, entre outras demandas. Essa constatação reforça que há uma tendência em nossa sociedade em naturalizar o cuidado como uma preocupação e uma função da mulher (KANTORSKI LP, et al., 2019).

Em relação às ocupações dos sujeitos do estudo, nenhum deles possuía vínculo formal de trabalho e muitos desempenhavam atividades informais para a sobrevivência. Eram pessoas de baixa renda, sendo quatro vendedores autônomos, uma dona de casa e um pedreiro. Este perfil de ocupações mostra como a questão do desemprego e dos subempregos são condições constituintes do mundo do trabalho na realidade de vida da população brasileira (MACHADO AS, 2018). Por um lado, isto afeta de maneira negativa a manutenção de condições satisfatórias de vida, mas por outro, no contexto da pesquisa, as tornam disponíveis para as atividades de cuidado junto aos familiares.

Essa dupla função, de trabalhadores e cuidadores, pode ser um dos vários fatores que contribuem para o isolamento destes sujeitos no seu cotidiano, como observado ao questionar se a entrevistada frequentava alguma atividade no território:

"Eu? Só é ir pra igreja, mesmo. Não tenho outra coisa... Não saio pra canto nenhum. Só vou pra Igreja dia de domingo e só (...). Não tenho muito tempo pra participar das outras coisas não". (Entrevistada 3). 
Como apontam Martins JCO, et al. (2012), o tempo laboral passa a ser a temporalidade principal da vida do trabalhador. Os demais tempos sociais do lazer, da convivência, que para os entrevistados precisam ser administrados junto com o cuidado ao familiar, tem sido diminuído. Essa questão sugere uma possível influência desfavorável na busca do acesso às redes de apoio, pois reduz os contatos e relações necessárias para a construção de vínculos na comunidade.

\section{As redes de apoio social dos familiares}

Percebeu-se que, de maneira geral, a rede de apoio social do cotidiano dos familiares entrevistados é bastante reduzida e pouco articulada. Para uma melhor compreensão do fenômeno, as falas foram organizadas em quatro categorias: 1- âmbito familiar; 2- CAPS ad; 3- serviços de urgência e emergência e hospitais psiquiátricos e 4- instituições religiosas.

\section{Categoria 1 - Apoio no âmbito familiar}

No que tange ao apoio familiar, a maioria relata ter recebido ajuda material, orientação ou aconselhamento de algum membro da família. Ao mesmo tempo, alguns relataram não poder contar com o auxílio dos parentes mais próximos. Isso sugere que nem sempre o fato de possuir vínculos familiares signifique a presença de apoio e a as funções de suporte que o caracterizam. Nesse sentido, apenas em alguns casos específicos, foram destacados os significados positivos da família como fonte de amparo e companheirismo.

"A minha companheira que convive comigo, ela é uma pessoa muito bacana, comigo e com meu filho que faz tratamento. Cuida muito bem dos meus filhos. (...) Ela senta e conversa com ele. Ela dá maior força. Nós três dentro de casa, a gente interage junto, a gente começa a conversar, trocar uma ideia" (Entrevistado 1).

"As pessoas que me ajudam mesmo são minha mãe e minha sogra... No momento mais difícil de faltar alguma coisa, de eu não ter alguma coisa, nem ele (o marido que faz tratamento), são elas que me dão. Elas me ajudam muito" (Entrevistada 4).

Tem sido comumente encontrado na literatura a confirmação que a família pode ser uma rede privilegiada de apoio (FONTES MMM, et al., 2012). No entanto, em outros casos, ela parece operar no sentido contrário à proteção, configurando-se como fator de risco quando os próprios integrantes são também usuários de substâncias psicoativas, conforme relatam outros entrevistados.

"Hoje? Meu único apoio é minha mãe. Porque, na família dela (a esposa que faz tratamento), todos usam fumo e bebida. Tem um irmão que é usuário de drogas também" (Entrevistado 2).

"Tem um outro irmão (do meu marido) que é professor de universidade, mas tem hora que não diz 'coisa com coisa' também (referindo-se a fala desorganizada e incompreensível quando está alcoolizado). Quando tira pra beber... bebe direto. Aí eu posso dizer o quê? Além dele, nisso desse vício de beber, ele tem todo o círculo da família" (Entrevistada 6).

Horta RL, et al. (2014) mostram que essa polaridade da família entre o risco e a proteção, permeia muitas situações na realidade das pessoas assistidas pelos serviços de saúde. Como a influência dos pares exerce papel potenciador importante no consumo de substâncias psicoativas, percebe-se que esta condição propicia, para alguns familiares, o aumento do sentimento de sobrecarga e tensão. Esta constatação reforça a necessidade de um olhar atento para o cuidado às famílias como parte integrante do cuidado em saúde mental.

\section{Categoria 2 - 0 apoio recebido nos Centros de Atenção Psicossocial (CAPS)}

Os CAPS, são serviços públicos de saúde mental formulados no SUS, possuem uma proposta de cuidados de base comunitária e norteados para o trabalho integrado a uma rede de serviços no território onde as pessoas vivem (LANCETTI A e AMARANTE P, 2014). Eles são vistos com grande consideração na opinião dos entrevistados. O CAPS ad, como serviço especializado acessado por nossos informantes, surge como importante fonte de apoio por prover medicamentos, apoio emocional, consultas especializadas, orientações e informações. 
Chama a atenção o fato de que estes equipamentos têm sofrido, nos últimos anos, um processo de subfinanciamento e sucateamento de suas estruturas. Isso foi observado durante a pesquisa, pois apresentava prejuízos na ambiência com salas pouco iluminadas, ventilação reduzida e paredes deterioradas. Além disso, o alto turn over dos profissionais da equipe, devido aos contratos de trabalho temporário, realizados por meio de seleção com duração de apenas dois anos agrava ainda mais a situação.

Esse desinvestimento tem sido notável com o passar do tempo, em decorrência do avanço de agendas neoliberais na gestão pública, desconstruindo funções próprias do Estado como tem indicado Vasconcelos EM (2012). Mesmo assim, diante destas limitações, os equipamentos conseguem obter uma visão positiva pelos familiares.

"Cara, pra mim, o CAPS foi um dos melhores programas que o governo inventou. Porque eu vou dizer uma coisa... Prefiro o CAPS do que uma Unidade de Pronto Atendimento - UPA (serviço de urgência e emergência). UPA? Pronto atendimento? Da onde? Você vem pra um pronto atendimento desse aí e nem recebido é? Aí muitas das vezes não tem médico. E o CAPS não só ajuda psicologicamente a pessoa como dá o suporte necessário. Se precisar de um encaminhamento, o cara tem aqui. Tenho certeza que ele lhe dá" (Entrevistado 1).

"Eu acho o CAPS excelente. Muito bom mesmo. O CAPS foi quem me salvou. Porque antes eu cheguei a pagar psiquiatra particular. Aí é que a gente se desespera, né? Por medo, também para ajudar, pagava médico, comprava remédio. O dinheiro não dava. Não dava certo" (Entrevistada 5).

"Minha filha, essa ajuda do CAPS, é uma maravilha, pra mim e pra todas as pessoas que vem aqui, eu acredito. Porque aqui fortificou minha convivência. Aqui eu tô me fortificando pra ajudar outras pessoas. Eu mando vir pra cá, ensino o caminho, entendeu? É tanto que eu tenho o que fazer na minha casa, mas eu deixo tudo. Quando eu cheguei em casa, já fui me organizando pra eu vir pra cá" (Entrevistada $6)$.

O CAPS se mostra para os entrevistados como um lugar de acolhimento. Embora, ocorra a falta de profissionais, ele é preferido pelos familiares pela capacidade das pessoas serem acolhidas em suas dimensões existenciais. E mesmo com a grande aceitação e reconhecimento positivos dos familiares, devese interrogar sobre as razões que levam as esferas governamentais a negligenciarem esses espaços.

Este vínculo essencial dos familiares com o CAPS ad parece proporcionar maior tolerância às limitações e precariedades que o serviço apresenta. Destaca-se, pois, como afirmam Constantinidis TC e Andrade NA (2015), que a oferta e a demanda de um serviço de saúde são construídas de maneira dinâmica, incluindo a objetividade e/ou subjetividade de seus atores, assim como suas falas e práticas no interior das instituições. Portanto, acredita-se que é a forma acolhedora como esta equipe específica conduz o cuidado, que parece gerar essa satisfação com o serviço.

\section{Categoria 3 - Apoio na rede de urgência}

Sobre o apoio recebido na rede de urgência, vários familiares reclamaram do atendimento das Unidades de Pronto Atendimento (UPA). Relatam que quando procuram esses serviços, não são acolhidos adequadamente pelos profissionais, principalmente por eles recusarem a atenção às pessoas que apresentem sintomatologia psiquiátrica.

"Na UPA, quando ela (a filha cuidada) estava em crise, eles falavam: 'Ó, aqui não é pra esse tipo de coisa. Vão para o hospital X.', indicavam o Hospital X (hospital psiquiátrico privado que mantém convênio com o SUS), ou então o Hospital $Y$ (hospital psiquiátrico público). Logo no começo a gente levava pra UPA. Como não tem apoio lá, a gente estava já levando direto pro Hospital Y" (Entrevistado 2). 
A situação descrita pelo familiar confirma uma realidade já constatada por Dimenstein M, et al. (2012) em estudo com profissionais de saúde. Os autores observaram que os serviços de urgência apresentam dificuldades em acolher essas demandas. Os profissionais tendem a não enxergar este equipamento como local para atendimento às situações urgentes em saúde mental. Uma das justificativas para a recusa tem sido a ausência de médico psiquiatra na equipe.

A resistência em atender as situações de crise demandadas por usuários de álcool e outras drogas nos serviços de urgência, demonstra um déficit na formação sobre saúde mental dos profissionais por ignorarem o manejo da crise psiquiátrica no conjunto das demais crises médicas. Além disso, sugere que o preconceito e a estigmatização sofridos pelos usuários de álcool e outras drogas, ainda são empecilhos para uma atenção integral das suas demandas (RONZANI TM, NOTO AR e SILVEIRA OS, 2015).

Em relação ao hospital psiquiátrico, reconhecido como apoio por alguns entrevistados, por um lado é apontado com avaliações negativas e por outro é visto como única alternativa diante das situações de crise dos seus familiares. Destacam a insuficiência de leitos para o contingente de pessoas atendidas, fazendo com que todos sofram com longas esperas e indefinição sobre os atendimentos. Em uma das falas foi possível identificar práticas negligentes realizadas nestes serviços.

"Amarravam ele, e ele é grandão (refere-se ao filho que foi internado). Aí quando "estrebuchou" ele deu 'um jeito' no braço (deslocamento articular). Aí eles falaram com o médico, que passou uns remédios. Mas, quando a gente chegou lá ele estava muito impregnado, todo urinado. Aí eu chamei a enfermeira e ela falou com o médico pra diminuir os remédios. Estavam dando muito remédio a ele. Aí ele veio melhorando. Com uns 15 dias, ele já estava melhor" (Entrevistada 3).

O próprio familiar, a quem empiricamente se costuma acusar de querer reduzir a sobrecarga vivida no cuidado do paciente, reage contra a prática institucional de superdosagens de medicações. $O$ relato deste familiar, embora tenha esboçado reação ao perceber o descuido, parece aceitar como uma fatalidade este tipo de tratamento.

A sobrevivência do hospital psiquiátrico nesta rede de saúde mental, mesmo com as notórias práticas iatrogênicas, é aceita pelos familiares sem maiores questionamentos. Considera-se que este tipo de acontecimento não deve ser naturalizado, pois como aponta Yasui S (2015), o cuidado em saúde mental tem a liberdade como princípio e exigência ética.

O usuário de álcool e outras drogas, que frequentemente é visto de maneira desumanizada e incapacitado de fazer qualquer tipo de escolha, acaba sendo alvo de ações de contenção e controle sobre seu corpo e seu desejo, retirando-Ihe qualquer possibilidade de autonomia. Isso indica essencialmente a problematização sobre a prioridade de reivindicar intensivamente, a inclusão e o aperfeiçoamento dos outros serviços de atenção às urgências, na produção do cuidado em saúde deste público, para que os hospitais psiquiátricos se tornem obsoletos.

\section{Categoria 4 - 0 apoio das instituições religiosas}

$\mathrm{O}$ apoio oriundo das instituições religiosas foi muito mencionado pelos entrevistados, que apontam ser esta uma rede de apoio social muito atuante no território. Vale ressaltar que o apoio social adquirido por meio das práticas religiosas pode promover o bem-estar e a sensação de proteção e cuidados em situações difíceis, funcionando como uma forma de conseguir forças para o equilíbrio das situações de estresse e sofrimento (HEREDIA LPD e SÁNCHES, 2013; VASCONCELOS EM e CAVALCANTE R, 2019; MURAKAMI R e CAMPOS CJG, 2012).

A prática religiosa foi constatada como uma alternativa que possibilita facilitar a convivência com o familiar usuário de drogas.

"Tenho Deus que é quem me sustenta em todas essas coisas. Eu passei o mês todinho de penitência, de oração, viu, firme e forte. Fiquei tanto que eu tomei essa decisão de não estar insistindo com ele. Tô calma, nunca fiquei sem dormir nenhuma noite. No começo eu ficava angustiada, todo tempo abrindo o portão, saindo lá fora, 
na calçada, pra ver se ele já tinha ido ou se ele ficava lá no bar... Eu participo de comunidade, eu participo da Legião de Maria, Coração de Jesus, eu visito dois dias na semana as casas do pessoal doente, pessoal idoso" (Entrevistada 6).

Assim, vê-se que a presença de instituições religiosas na vida dos usuários e familiares requerem maior compreensão por parte dos trabalhadores da saúde mental. Pois, como afirmam Vasconcelos EM e Cavalcante R (2019), as instituições religiosas fazem parte das estratégias populares de enfrentamento as situações sociais e existenciais limites.

No entanto, a consideração desta presença não deve ignorar o caráter paradoxal do apoio social realizado pelas religiões, sobretudo as evangélicas neopentecostais. Isso porque, ao mesmo tempo em que oferecem assistência, algumas dessas instituições, produzem também fomento às situações de intolerância, perpetuam preconceitos e desrespeito a outros modos de vida.

Inclusive, um dos entrevistados relatou sua insatisfação sobre a visão desfavorável de condutas existentes em alguns espaços religiosos que não corresponderam com suas necessidades de apoio.

"Então, eu acho assim... As igrejas evangélicas, por esse negócio de toda hora ficar pedindo 'Ah, é dízimo, é isso e aquilo, é uma ajuda...'. Eles têm uma 'pedição' muito grande de dinheiro. Mas quando se precisa de alguém para cuidar, apoiar, num caso como esse aqui, não aparece ninguém" (Entrevistado 2).

Essa sensação de abandono dentro da religião evidenciada, também é suscetível de ocorrer com outros familiares, que, em momentos de intensa crise, abandonam as práticas religiosas tradicionais e trocam por outras formas de manifestação da espiritualidade (SILVA L e MORENO VA, 2004).

É interessante observar que, entre as lacunas deixadas pelo poder público, as instituições religiosas se expandem como rede de apoio informal ao sofrimento das famílias. Como apontam Arenari B e Dutra $\mathrm{R}$ (2016), no vazio de alternativas efetivas, as igrejas atuam rompendo o círculo de exclusão no qual estas pessoas estão submetidas, incluindo-as em outras perspectivas e projetos que recuperam sua dignidade e reconhecimento social.

Esta situação revela a problemática das políticas públicas para os sujeitos que consomem drogas em não proverem apoio suficiente e próximo do seu cotidiano, revelando assim a necessidade de integração das redes de atenção à saúde ao contexto comunitário e suas fontes de apoio, como sugerem Pereira LB, Costa PHA e Ronzanni TM (2016).

Sendo assim, ao observar as diferentes redes de apoio social utilizadas pelos entrevistados, vê-se a importância das ações de saúde mental desenvolvidas pelas políticas públicas para pessoas com problemas decorrentes do uso de drogas e seus familiares, devam estar articuladas com diferentes espaços sociais, devendo ultrapassar as fronteiras sanitárias, não ficando restritas apenas aos serviços de saúde (DIMENSTEIN M e LIBERATO M, 2011).

\section{CONSIDERAÇÕES FINAIS}

As redes de apoio social presentes nos territórios dos sujeitos desta pesquisa são constituídas unicamente pelo contexto familiar e seus entes, pelo CAPS ad, UPA e hospital psiquiátrico, assim como pelas igrejas. Constatou-se que os parentes, mesmo com certa ambiguidade nas relações, onde em alguns momentos se configuram como fator protetivo e em outros como fator de risco, e as instituições religiosas, por meio da ajuda concedida em suas relações informais, apresentaram potencialidades em relação a oferta de assistência emocional, material e inclusão social. Por outro lado, a insuficiência na atenção às urgências, com pouca oferta de serviços às demandas de crise, faz com que os familiares busquem a internação em hospitais psiquiátricos e a medicalização como únicas alternativas, mostrando assim fragilidades das instituições formais de apoio. O repertório reduzido de redes sociais de apoio acessado pelos sujeitos deste estudo impõe a reflexão sobre a urgência de construir novas compreensões sobre outros espaços do território, que podem ser produtores de diferentes modos de acolher e cuidar, envolvendo a pessoa que usa drogas, sua família e a comunidade. 


\section{REFERÊNCIAS}

1. ARENARI B, DUTRA R. A religião e sua vocação na recuperação de usuários do crack: "os longos futuros". In: SOUZA J, organizador. Crack e exclusão social. Brasília: Ministério da Justiça e Cidadania, Secretaria Nacional de Política sobre Drogas; 2016. 360p.

2. BARDIN L. Análise de conteúdo. Lisboa: Edições 70; 2011. 229p.

3. BERNARDES A. Territorio y acceso: cuestiones sobre las políticas de salud brasileñas. Avances en Psicología Latinoamericana, 2017; 35(2): 339-349.

4. BOSI MLM. Pesquisa qualitativa em saúde coletiva: panoramas e desafios. Ciênc. Saúde Colet, 2012; 17(3): 575-586.

5. CONSTANTINIDIS TC, ANDRADE AN. Demanda e oferta no encontro entre profissionais de saúde mental e familiares de pessoas com sofrimento psíquico. Ciênc. Saúde Colet., 2015; 20(2): 333-342.

6. DIMENSTEIN M, et al. $O$ atendimento da crise nos diversos componentes da rede de atenção psicossocial em Natal/RN. Rev. polis psique., 2012; 2(3): 95-127.

7. DIMENSTEIN M, LIBERATO M. Desinstitucionalizar é ultrapassar fronteiras sanitárias: o desafio da intersetorialidade e do trabalho em rede. Cad. bras. saud. ment., 2011; 1(1): 212-222.

8. FONTES MMM, et al. Funcionamiento familiar y su relación con las redes de apoyo social en una muestra de Morelia, México. Salud ment., 2012; 35(2): 147-154.

9. GALVÁN J, SERNA G, HERNÁNDEZ A. Aproximación de las redes sociales: una vía alterna para el estudio de la conducta de uso de drogas y su tratamiento. Salud ment., 2008; 31(5): 391-402.

10. GASKELL G. Entrevistas individuais e grupais. In: BAUER MW, GASKELL G, editores. Pesquisa qualitativa com texto, imagem e som: um manual prático. Petrópolis: Vozes, 2002. 520p.

11. GASPARD JL, LARGACHA SMR. Drogadicción y aislamiento social: reflexiones sobre la atención a drogadictos en Francia y Colombia. Avances en Psicología Latinoamericana, 2016; 34(2): 315-338.

12. HEREDIA LPD, SÁNCHEZ AIM. Spirituality and low-risk consumption of alcohol in young adults. Invest. educ. enferm., 2013; $31(2): 287-294$.

13. HORTA ALM, et al. Vivência e estratégias de enfrentamento de familiares de dependentes. Rev. Bras. Enferm, 2016; 69 (6): 1024-1030.

14. HORTA RL, et al. Influência da família no consumo de crack. J. Bras. Psiquiatr., 2014; 63(2): 101-112.

15. KANTORSKI LP, et al. Gênero como marcador das relações de cuidado informal em saúde mental. Cad. Saud Colet., 2019; 27(1): 60-66.

16. LANCETTI A, AMARANTE P. Saúde mental e saúde coletiva. In: CAMPOS GWS, et al. Tratado de Saúde Coletiva. 2nd ed. São Paulo: Hucitec, 2014; 967p.

17. MACHADO AS. O caracol e sua concha: ensaios sobre a nova morfologia do trabalho. PEGADA-A Revista da Geografia do Trabalho, 2018; 19 (1): 211-215.

18. MARTINS JCO, et al. De Kairós a Kronos: metamorfoses do trabalho na linha do tempo. Cad. psicol. soc. trab., 2012; $15(2): 219-228$.

19. MURAKAMI R, CAMPOS CJG. Religião e saúde mental: desafio de integrar a religiosidade ao cuidado com o paciente. Rev. bras. enferm., 2012; 65 (2): $361-367$.

20. PEREIRA LB, et al. As redes sociais no cuidado aos usuários de drogas: revisão sistemática. Psicol. estud., 2016; 21(1): $29-39$.

21. RONZANI TM, et al. Reduzindo o estigma entre usuários de drogas: guia para profissionais e gestores. Juiz de Fora: Editora UFJF: 2015; 24p.

22. SILVA L, MORENO V. A religião e a experiência do sofrimento psíquico: escutando a família. Ciênc. cuid. saúde., $2004 ; 3(2): 161-168$.

23. VASCONCELOS EM. Crise mundial, conjuntura política e social no Brasil, e os novos impasses teóricos na análise da reforma psiquiátrica no país. Cad. bras. Saud. ment., 2012; 4(8): 08-21.

24. VASCONCELOS EM, CAVALCANTE R. Religiões e o paradoxo apoio social-intolerância, e implicações na política de drogas e comunidades terapêuticas. São Paulo: Hucitec, 2019. 392p.

25. YASUI S. Entre o cárcere e a liberdade: apostas na produção cotidiana de modos diferentes de cuidar. In: Brasil, Caderno Humanizasus: Saúde mental. Brasília: Ministério da Saúde; 2015. 548p.

26. YUNES MAM, JULIANO MCC. La importancia de las redes de apoyo en la promoción de la salud y resiliencia comunitaria. In: SAFORCADA ET, SARRIERA JC, ALFARO IJ organizadores. Salud comunitaria desde la perspectiva de sus protagonistas: la comunidad. Buenos Aires: Nuevos Tiempos, 2015. 318p. 